ID_INVESTIGACIONES

\title{
PAISAJES DE ORO: enclaves de la zona rural-costera
} de Canelones

\author{
Luciana Echevarría y Paloma Nieto \\ Arquitectas, Master en Manejo Costero Integrado \\ Docentes Asistentes Taller, Facultad de Arquitectura UdelaR
}

\section{RESUMEN}

El presente trabajo se plantea indagar a través del análisis del paisaje el vínculo que ha existido entre la playa, el área rural y las distintas urbanizaciones presentes en la zona costera del Departamento de Canelones, "Costa de Oro" ${ }^{1}$. El paisaje es entendido aquí como fuente de información de los procesos sobre un territorio. Su estructura territorial, aparece como síntesis de los sistemas ecológicos y culturales que lo constituyen, resultado del proceso de transformación del ambiente en el correr del tiempo.

El área de estudio se podría definir como una zona de confluencia e interrelación costera, terrestre y marina. Los usos en esta faja costera están explícitamente bajo tutela del Estado y tienen la característica de permitir el acceso público para el disfrute de todos los ciudadanos. Nuestro aporte es una mirada diferente sobre ese territorio. Para esto elaboramos una metodología que permitió hacer operativa una nueva forma de mirar el área, trabajando a partir de la complejidad geográfica, histórica y morfológica del territorio, asumiendo la fragilidad y el dinamismo del sistema costero.

\footnotetext{
1 "Costa de Oro" es la denominación que reciben una sucesión de balnearios, al Este de Montevideo, ubicados entre el Arroyo Pando y el Arroyo Solís Grande. Esta zona se caracteriza por sus largas y anchas playas de arenas blancas y muy finas (de aquí su denominación), a orillas del Río de la Plata.
} 


\section{ID_INVESTIGACIONES}

Frontera móvil entre la tierra y el mar, entre lo sólido y lo líquido, la costa constituye un tipo de paisaje cuya interpretación ha variado a lo largo de la historia. A partir de las últimas dos décadas del siglo $\mathrm{XX}$, nuestras costas pasan a ser objeto de planificación territorial con el convencimiento de que este nuevo espacio generado para uso del hombre concretaba la utopía de recomponer la armonía perdida entre el hombre y la naturaleza (Torres, 2007).

Palabras clave: procesos territoriales, paisaje costero-rural, sistemas ecológicos.

\section{ABSTRACT}

The present research aims to investigate through the analysis of landscape, the bond between the beach, the rural area and the different urbanizations in the coastal zone of the Department of Canelones, "Costa de Oro". Landscape is understood here as a source of information for a set of processes within a territory. Its territorial structure appears like a synthesis of the cultural and ecological systems that constitute it, as a result of the environment's transformation process through time.

The area of study could be defined as a zone of confluence and marine, land, and coastal interrelation. The activities within this coastal zone are explicitly under guardianship of the State and they have the characteristic of assuring public access for the enjoyment of all citizens. Our contribution implies a different look on that territory.

For this reason we developed a methodology that allows a new interpretation of the area, working from the morphological, historic, and geographical complexity of the territory, and assuming the fragility and the dynamism of the coastal system. 


\section{ID INVESTIGACIONES}

Dynamic border between the land and the sea, between the solid and the liquid, the coast constitutes a type of landscape whose interpretation has changed along history. From the last two decades of the 20th century, our coasts have become an object of territorial planning with the conviction that this new space generated for the use of humans, summarized the utopia of recomposing harmony loss between man and nature (Torres, 2007).

Key words: land processes, coastal and rural landscapes, ecological systems

\section{INTRODUCCIÓN}

Este artículo sintetiza un estudio de carácter analítico que a través del enfoque del Paisaje Cultural, tiene como objetivo proporcionar una nueva mirada sobre los procesos de transformación-producción del territorio que permita pensar nuevas estrategias de desarrollo. En este sentido creemos que la dimensión del Paisaje Cultural constituye un aporte al enfoque del Manejo Costero Integrado ${ }^{2}$. Se propone un recorrido histórico-analítico por el área de estudio, organizado en tres bandas paralelas al borde costero: banda rural, balnearia y estuarina, así como por distintos corredores que cruzan este territorio.

Los procesos de transformación-producción del territorio (Pumain, 2003) tienen algunas características básicas: son procesos históricos acumulativos, sociales y también ambientales. Su resultado en un momento determinado nos muestra el "estado actual" de lo que podemos definir como sistema territorial: los balnearios, centros poblados, actividades económicas, productivas, entre otros,

${ }^{2}$ El Manejo Costero Integrado es un proceso dinámico de toma de decisiones para el uso, desarrollo y protección de áreas y recursos costeros, a través de objetivos definidos en cooperación con los usuario nales, regionales y locales. recursos para las generaciones actuales y futuras. (Knechty Atcher, 1993). 


\section{ID INVESTIGACIONES}

y el modo de reproducirse en una sociedad y tiempo determinada, incluyendo las relaciones físico ambientales, sociales, económicas que definen las características de este espacio y sociedad.

Específicamente en territorios costeros, éstas miradas, confluyen con los enfoques provenientes del Manejo Integrado, focalizándolos en su dimensión patrimonial ambiental particular y en el sistema ambiental costero, como paisaje, como soporte de usos múltiples, como ambiente natural y cultural. En dichos enfoques la incorporación del hombre (en comunidad) como parte del ambiente costero es una estrategia que nos permite relacionar sus formas de operar en el territorio con los procesos físicos naturales.

Desde los orígenes, el Río de la Plata ha sido clave en el desarrollo del proceso histórico del país como fuente inicialmente asociada a los recursos provenientes de la ganadería "vaquería del mar" a partir de la introducción del ganado por Hernandarias (1611 y 1617), y de su función estratégica para el dominio continental y acuático de la región (Gallicchio et al, 2004). Se establecen entonces las primeras poblaciones y las actividades portuarias asociadas al uso militar y relacionada con la navegación en el Río de la Plata (Lezama, 2009). Es así que el mar y los territorios costeros han tenido siempre una decisiva importancia en el desarrollo de nuestra cultura y la historia está marcada por la relación tan directa que tiene nuestro país con el Río de la Plata.

La costa estuarina constituye en nuestro caso un tipo de paisaje cuya interpretación ha variado notablemente a lo largo de la historia, siendo objeto de diseño paisajístico en nuestro país a partir de las dos últimas décadas del siglo XIX. Así las desavenencias entre tierra y mar fueron amortiguadas por medio de extensas plantaciones de pinos, eucaliptos y tamarices destinados a fijar los médanos y a dar sombra a los visitantes. Los impactos generados en el espacio costero por las obras de infraestructura y producto de la sobrecarga de 


\section{ID INVESTIGACIONES}

la matriz territorial dada por otros usos, evidenciará que aún se estaba lejos de la armonía hombre naturaleza.

\section{ANTECEDENTES LOCALES GENERALES Y PROBLEMÁTICA}

Nuestra área de estudio se encuentra ubicada en la zona costera del Departamento de Canelones y abarca el territorio desde el Arroyo Solís Chico y el Arroyo Solís Grande (de Este a Oeste), la ruta 8 al norte y el límite de 7 millas náuticas hacia el Río de la Plata (ver figura 1).

Cuenta con 18 centros poblados (rurales y balnearios) y $27 \mathrm{Km}$ de costa, abarca aproximadamente $400 \mathrm{~km} 2$ de área terrestre y $60 \mathrm{~km}^{2}$ de área estuarina. La población aproximada es de 10.390 personas, de las cuales 8.513 viven en áreas urbanas y 1.877 en áreas rurales. Este departamento tiene una superficie total de $4.536 \mathrm{~km}^{2}$, y una población total de 485.240 habitantes. Entendemos este espacio costero con límites flexibles, ya que está inmerso en sistemas territoriales más amplios como la cuenca del Río de la Plata exterior, el litoral costero uruguayo, las respectivas micro cuencas o la ruta 8 . Esta es considerada como un límite territorial flexible que nos permite involucrar aquellas áreas al Norte de la misma que entendemos aportan a la dinámica socioeconómica local y pertenecen a las micro cuencas de los arroyos Solís Chico y Grande.

Típicamente este segmento de la costa uruguaya está dominado por arenales y barrancas. Los parches de vegetación nativa se encuentran asociados a los bañados y arroyos que desembocan al Río de la Plata.

Los procesos históricos son relevantes para entender la situación actual del área de estudio. A fines del siglo $\mathrm{XIX}$ y principios del siglo $\mathrm{XX}$, se concretan importantes obras de infraestructura en el Uruguay, entre ellas el puerto, el tren 


\section{ID_INVESTIGACIONES}

el inicio de la red vial, frigoríficos, etc. (Musso, 2001). La llegada del ferrocarril a la zona inicia un proceso de desarrollo comercial y productivo.

En 1895 se construye el Ferrocarril Uruguayo al Este, pasando el arroyo Solís Grande, la llamada Estación La Sierra, y la Estación Las Toscas a la altura del actual $\mathrm{Km} 59$ de ruta Interbalnearia. Se empiezan a formar así los primeros balnearios de la costa de Canelones, conectados con la capital por la línea férrea a Maldonado (Musso, 2001).

En el área rural los nuevos centros poblados que se forman en este período resultan en general de asentamientos en torno a la estación de ferrocarril. Se concentran allí actividades de trasbordo, a las que se añaden otras, permitiendo la radicación de la población.

En la zona costera el desarrollo comercial a partir del Arroyo Solís chico al Este, se inicia poco después a partir de la intervención del Dr. Miguel Perea, quien alrededor de 1906, inspirado en la obra desarrollada en Maldonado por el Dr. Lussich, compra una amplia faja de arenales con el propósito de conformar una unidad balnearia.

Algunos años mas tarde, a partir de la década del 30 empiezan a surgir en la zona numerosos centros balnearios. Este proceso continuó desarrollándose y se intensificó con las mejoras de la infraestructura vial y de los sistemas de transporte.

La lógica histórica de ocupación del espacio costero que surge a partir de la construcción del ferrocarril, las conexiones Este-Oeste -inicialmente a partir de la ruta 8 (antiguo Camino a Maldonado)- y posteriormente con la Interbalnearia, las conexiones Norte-Sur que derivan en algunos casos de la vía férrea hasta la costa, y los procesos ambientales -como la dinámica de dunas, los humedales costeros, los sistemas fluvio-estuarinos y los corredores biológicos, entre otros- nos hacen entender a este territorio como una unidad indisociable. 


\section{ID_INVESTIGACIONES}

\section{SOPORTE}

Los $460 \mathrm{~km}^{2}$ que definen el territorio objeto de este trabajo, están compuestos por un $87 \%$ de área terrestre y un $13 \%$ de área marina. Del total de la superficie un 5 a un $10 \%$ corresponde a humedales de agua dulce (ver figura 2)

Con respecto a la orografía del Departamento, podemos decir que es un territorio con un relieve apenas ondulado o de llanuras. En la costa la acción del mar ha dado diversas formas al material arcilloso, llegando a crear en algunos casos cárcavas remontantes.

Las características geomorfológicas principales de este tramo son, en primer lugar las playas $y$ cordones en el tramo comprendido entre las desembocaduras de los arroyos Solís Chico y Sarandí; en segundo lugar las dunas, formaciones eólicas presentes en gran parte del tramo de estudio, y en tercer lugar las barrancas sedimentarias.

En cuanto a la hidrografía del departamento podemos aportar que tiene un sistema de arroyos de escaso caudal que desembocan en el mar. Se destacan: Solís Chico, Solís Grande, Sarandí, La Tuna, El Bagre, La Coronilla, desembocando todos ellos en el Río de la Plata.

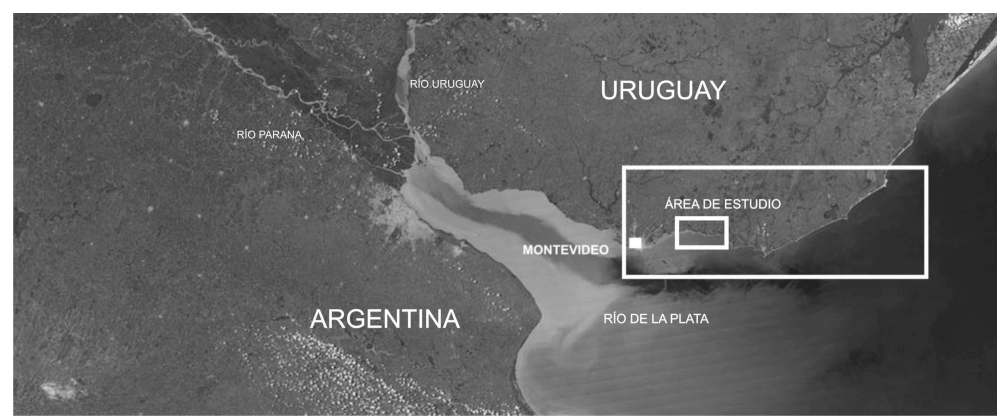

Ubicación del área de estudio Fuente: Jacques Descloitres MODISRapid Response Team, NASA/GSFC 
ID_INVESTIGACIONES

\section{PAISAJE CULTURAL Y PATRIMONIO}

La incorporación de la categoría de paisaje cultural al estudio del área nos permite comprender cuales son las relaciones existentes entre los grupos humanos que se vinculan a este territorio, los diferentes tipos de apropiación y uso, y los grados de consolidación que estos tienen.

Desde la mirada de un desarrollo sostenible de la zona costera asignada, este estudio nos exigió una comprensión dinámica de los procesos culturales y su relación con los sistemas biofísicos que allí existen, permitiéndonos incluir al hombre como parte del ecosistema, en tanto agente de modificación, superando la brecha tradicional entre el medio físico y cultural. En este sentido coincidimos con la definición de Sauer: el paisaje cultural es creado por un

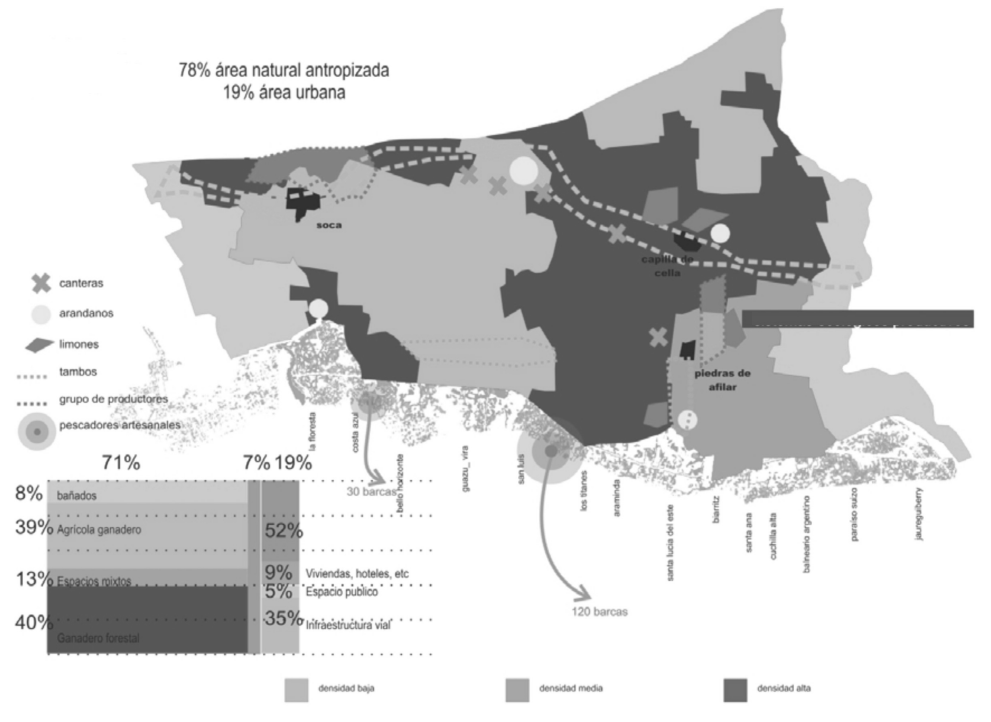

Caracterización del área. Principales sistemas productivos en el área de estudio 


\section{ID_INVESTIGACIONES}

grupo humano o cultural a partir del paisaje natural. La cultura es el agente, el área natural el medio, el paisaje cultural el resultado.

El paisaje es tomado entonces como fuente de información de los procesos sobre un territorio, es la manifestación externa de estos procesos. El paisaje natural junto con el hombre como agente de modificación, es lo que expresa el paisaje cultural (Sauer, 1925).

Por otro lado el concepto de patrimonio como valor colectivo ha evolucionado a lo largo del siglo XX, hasta englobar el paisaje considerado hoy como recurso colectivo y patrimonial. Cabe destacar que el paisaje en tanto que patrimonio posee la cualidad de reunir valores colectivos de distinto tipo: natural y cultural, muchas veces indisociables. Creemos que todo paisaje posee un valor como patrimonio colectivo. En este sentido este estudio intenta contribuir al conocimiento del paisaje cultural del área de estudio y a su puesta en valor. La interpretación del patrimonio representa un sistema de aproximación a la cultura. En este sentido el trabajo asume su condición histórica, en cuanto a la valoración y construcción de la mirada que propone sobre el paisaje de estudio.

En las clasificaciones derivadas del análisis se construyeron diferentes dominios, con el fin de comprender e interpretar, a través de datos de la realidad actual, cuáles habían sido y son los procesos. El primero incluye los tipos de estructuras construidas por el hombre para la definición de su hábitat y su alojamiento, ya sea disperso como ocurre en nuestro tramo de costa o aglomerado.

En esta clasificación encontramos por un lado categorías específicas del tipo de asentamiento para explorar a través de distintas variables (localización de centros poblados, vínculo entre éstos, estructura física y forma urbana) sus relaciones con el soporte físico, y diversas infraestructuras asociadas a los 
ID_INVESTIGACIONES

desarrollos antrópicos (matriz productiva, sistemas de movilidad). En segundo lugar están las categorías que exploran la dimensión simbólica del paisaje, asociado al mundo de las ideas y generador de identidad para una comunidad o cultura. Estas categorías incorporan monumentos aislados, ambientes urbanos o productivos característicos, y sitios de valor arqueológico o natural específico.

\section{ABORDAJE METODOLÓGICO}

La estrategia para desarrollar este proceso, fue la de explorar y analizar la información disponible sobre el área. A través de distintas técnicas, tales

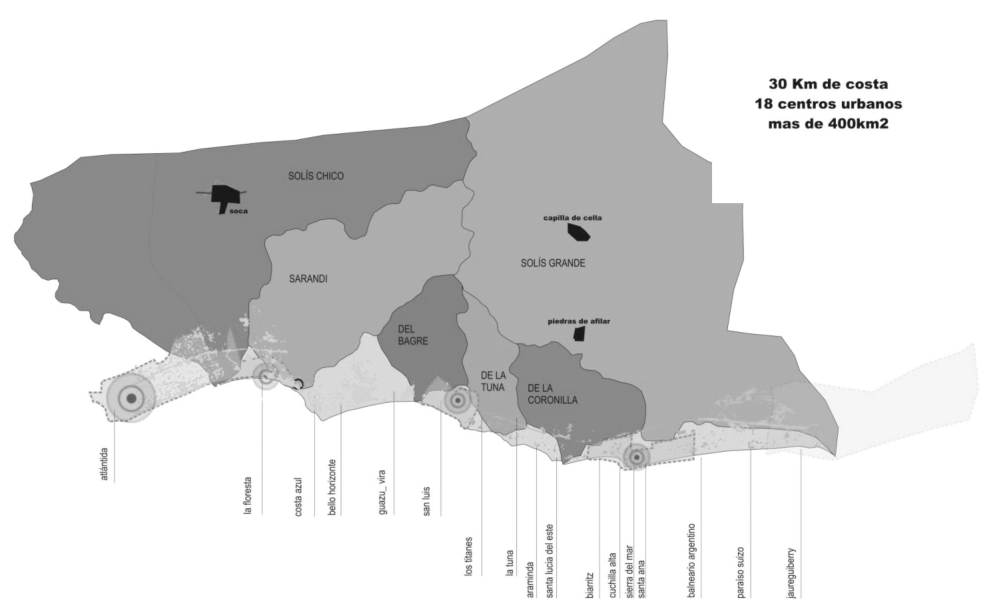

Sistema de cuencas 


\section{ID_INVESTIGACIONES}

como observación participante, salidas de campo, revisión bibliográfica, análisis de información secundaria, entrevistas semi-estructuradas a actores locales, a instituciones públicas y privadas que operan en el área, tratamos de describir la manera en que la sociedad se relaciona, ocupa y transforma este espacio costero. El entorno físico, el patrimonio, la producción, las infraestructuras, los sistemas de conexión, el marco normativo, institucional y social son aspectos que inciden y condicionan la forma de ocupar este espacio. Aquí nos centraremos en su dimensión como paisaje cultural.

Para el análisis de éste se propone una lectura del territorio a partir de la definición de tres bandas paralelas: banda rural, banda balnearia y banda estuarina (ver figura 4) por entenderse que, si bien están interconectadas, constituyen en términos de paisaje unidades diferenciadas. Se analizan también los corredores, tanto físicos (rutas, caminos, entre otros) como biológicos ${ }^{3}$ (cursos de agua, montes ribereños, humedales, cordones dunares) que estructuran el área en el sentido perpendicular a la costa.

\section{Banda Rural}

Este sector de territorio del departamento de Canelones es bastante desconocido, tanto por los pobladores de Montevideo, a pesar de que usan su faja costera como centro de ocio desde hace casi un siglo, como por gran parte de los pobladores de otras regiones rurales de este departamento que se caracterizan por no practicar gran turismo interno.

A pesar de esto, esta comarca rural se encuentra a solo una hora de Montevideo, a menos de una hora desde Piariápolis, y está enmarcada por dos grandes vías que son la Interbalnearia y la Ruta $N^{\circ} 8$. Hasta fines del siglo XIX

\footnotetext{
${ }^{3}$ Los corredores biológicos surgen como un mecanismo que busca dar mayor viabilidad a la conservación de las especies que se encuentran en las áreas silvestres. Su objetivo es permitir el desplazamiento de ecosistema (o hábitat) (García 1996). Caracterización usada por la UICN (Unión Internacional para la Conservación de la Naturaleza).
} 


\section{ID_INVESTIGACIONES}

el área estaba destinada a un uso agrícola ganadero, siendo esta región la primera en incorporar la agricultura en nuestro país.

A finales del siglo XIX y principios del siglo XX se concretan a nivel nacional importantes obras de infraestructura en nuestro país, entre ellos el puerto, el ferrocarril, el inicio de la red vial o los frigoríficos. Como dijimos, en nuestra área de estudio la llegada del ferrocarril inicia un proceso de desarrollo comercial y productivo que comienza en 1895 cuando se construye el Ferrocarril Uruguayo al Este. Surgen así los primeros nodos de servicios vinculados a las paradas y estaciones del tren, algunos de los cuales derivan posteriormente en centros poblados. La tecnología genera una nueva colonización del área, superponiendo una lógica estructural de uso y organización del territorio, diferente a la existente. A partir de este momento a la matriz territorial productiva se le superpone la traza del tren, que organizará la red de centros poblados resultantes en general de asentamientos en torno a la estación de ferrocarril. Se concentran allí actividades de trasbordo, a las que se añaden otras, permitiendo la radicación de la población. Tal es el caso de la estación Mosquitos (Soca), estación Floresta y estación Piedras de Afilar. Así se empiezan a formar los primeros balnearios de la costa de Canelones,

Atlántida 1912, conectado a la capital por la línea férrea a Maldonado y La Floresta en 1915, cuyo fraccionamiento se realiza una década después.

Actualmente la lógica de este territorio se asemeja a la de una isla ya que las conexiones Norte y Sur que lo vinculan con el resto del departamento han dejado de tener sentido al perderse el rol de algunas de las centralidades de referencia (por ejemplo con Soca, antiguo centro administrativo). La zona rural de esta microrregión se caracteriza por contar con un conjunto de centros poblados, con escaso desarrollo urbano y con predios productivos de una escala intermedia. 
ID_I N VESTIG AC I O NES

A excepción de Soca, los núcleos son auténticos pueblos rurales, algunos apenas caseríos, con una morfología particular dada por existencia de viviendas alrededor de la vía junto con la estación y con ausencia del espacio plaza. Esta tipología de asentamiento es diferente a la del característico pueblo o ciudad del interior del país. La mayoría son centros de pequeños servicios al resto de la población rural y cuentan hoy con escasa población. Los núcleos son los puntos de una red que hoy sin la presencia del tren (que la atravesaba en el sentido Este-Oeste) se encuentra desactivada.

La red secundaria de carreteras constituye un tejido que cubre uniformemente el territorio, atravesando esta "isla" en el sentido Norte-Sur, vinculando los dos conectores. En esta red se destaca el tramo vial que une Piedras de Afilar y Capilla de Cella través de la Ruta $N^{\circ} 70$, que se encuentra en la Loma de la Cuchilla, dándole un carácter panorámico, oficiando de mirador natural, permitiendo unas vistas excepcionales del paisaje con visuales que alcanzan la costa.

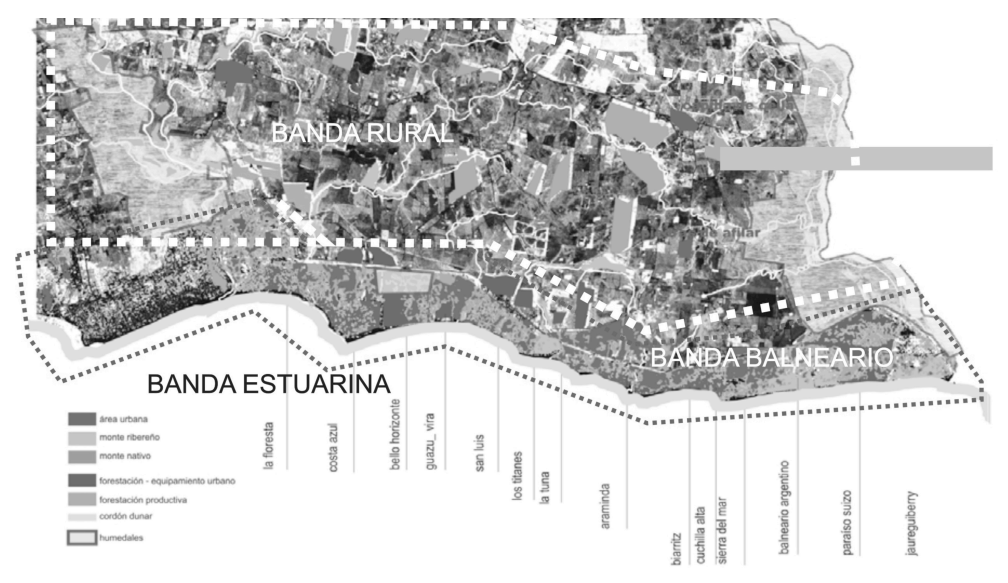

Definición de bandas de análisis 


\section{ID_INVESTIGACIONES}

Otros estructuradores de la zona son los arroyos. En extensos tramos las márgenes de estos arroyos poseen una vegetación nativa abundante (monte ribereño) y son importantes generadores de hábitat y biodiversidad, ya que actúan como corredores naturales, cumpliendo importantes servicios ambientales, al igual que los humedales existentes en grandes áreas, asociados a los dos principales arroyos (Solís Chico y Solís Grande), caracterizados por sus plantas acuáticas y aves singulares.

El paisaje en esta banda está muy asociado a la producción de la zona. El tamaño de sus predios y la diversidad productiva actual caracterizan esta región con sus superficies plantadas de tomates, arándanos, limones, grandes praderas naturales y artificiales dedicadas al pastoreo, predios forestados $y$ algunos relictos de bosque natural que conforman un atractivo paisajístico. En gran medida la diversidad productiva existente se asocia a una serie de proyectos de desarrollo local existentes (propiciados por la intendencia y articulados por la junta local), tendentes a conseguir un desarrollo económico que retenga a los productores de la zona.

\section{Banda Balnearia}

La franja costera por su característica de suelo arenoso fue poco apta para el uso agropecuario, por lo cual permaneció por mucho tiempo despoblada. El desarrollo comercial de esta zona costera a partir del Arroyo Solís chico al Este, se inicia a partir de la intervención del Dr. Miguel Perea, quien alrededor de 1906, compra 576 ha de una amplia faja de arenales comprendida entre los arroyos Solís Chico y Sarandí y desde el pueblo Mosquitos, hoy Soca, hasta el Río de la Plata.

En 1908 se realizan las primeras obras de antropización con el objetivo de fijar las dunas (ver figura 5). Se plantan pinos marítimos traídos de Galicia y Portugal, eucaliptos y acacias traídas del sur de Francia. En marzo de 1911 el 


\section{ID_INVESTIGACIONES}

Dr. Perea constituye una Sociedad Anónima de arboricultura, balneario y fomento territorial, llamada "La Floresta". Posteriormente se inicia la fundación de los diferentes balnearios que componen el área. Se aprecia así el temprano propósito de usar con esta finalidad (centro balneario) la costa del departamento lo que se generaliza a partir de la década del 50. Posteriormente se inició la fundación de los diferentes balnearios que componen el área.

En la década del 30 surgen numerosos balnearios en las costas del departamento de Canelones. Al Este del Arroyo Solís Chico se fraccionan Cuchilla Alta, Costa Azul, Santa Lucia del Este, Los Titanes, La Tuna, Biarritz y Jaugueryberry. Con posterioridad a 1945 los fraccionamientos ocupan sectores cada vez más extensos de la franja costera, con los consiguientes cambios en las condiciones del lugar. El desarrollo de muchos de estos balnearios se intensifica en las décadas del 60 y 70 con las sucesivas mejoras viales y del parque automotor, así como con el auge generalizado de la actividad turística. Esto lleva a una mejora en la calidad de los servicios y facilita también la radicación de población permanente (Musso, 2001).

Es interesante destacar como se sucede la fundación de cada uno de los balnearios y se va desarrollando la urbanización. La zona de estudio tiene un sostenido aumento tanto de las construcciones como de la población permanente. Este proceso de colonización costera fue acompañado por la creación de otros balnearios, que si bien estaban fuera del área de estudio ayudaron a consolidar "la playa" como una nueva modalidad de ocio cultural. Se destacan varias nuevas urbanizaciones de excelente nivel que corresponden a actividades turísticas y emplazamientos relevantes: el Arquitecto Gómez Gavazo en La Paloma (1946), Bonet en Portezuelo (1950), Cravotto en Pinamar (1947). Sin embargo, en la costa canaria estos emprendimientos no tienen esa relevancia a pesar de la promoción turística e 
inmobiliaria que se realiza en ese momento en algunos de ellos, como en el caso del Balneario Argentino, aún hoy escasamente urbanizado.

Desde su condición geográfica, los balnearios se encuentran en un emplazamiento costero, en general con playas y eventualmente sectores rocosos, es un territorio heterogéneo en sus situaciones de borde, con grandes intersticios costeros fisurado por arroyos (ver figura 6).

El área de estudio se caracteriza por tener una continuidad de fraccionamientos balnearios. La trama urbana propuesta en varios de ellos es de tipo pintoresquista, o en damero, atravesado por un eje principal a la rambla y ejes secundarios diagonales. En ambos el espacio rambla proyectado juega un papel relevante. Debido a la irregular colmatación que han tenido estos balnearios, en muchos de los cuales persisten todavía grandes áreas sin ocupar, se opta por definir las siguientes categorías de análisis: expandido/compacto (se refiere a la densidad de ocupación de la trama), lineal costero o perpendicular a la costa (se refiere a como se organiza la trama en relación al borde costero).

Se considera asimismo en cada caso según su relevancia, el vínculo con el borde costero, con otros centros balnearios y con la Ruta Interbalnearia, la presencia de manchas de bosque, y tipología arquitectónica singular. En su mayoría la arquitectura está compuesta por viviendas unifamiliares tipo chalet, con gran presencia de la tipología económica brindada por la Intendencia.

La Floresta, Costa Azul, Bello Horizonte. El balneario de La Floresta se organiza a través de una rambla a la cual se agregan extensiones secundarias, Costa Azul y Bello Horizonte: "estructura lineal con agregado". Su trama es en base a una combinación de radiales y diagonales, la trama urbana queda como resultante, generando plazas en las intersecciones. La Rambla Dr. Perea continua en Rambla José Artigas el área urbanizada se extiende en la dirección

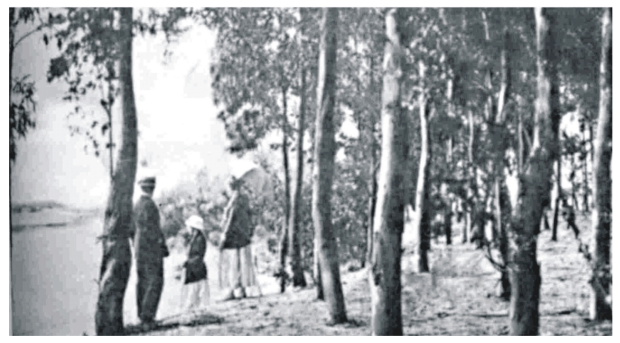

Inicio del balneario. Foto de archivo 


\section{ID_INVESTIGACIONES}

dada por la tensión costera. Existe una presencia de grandes áreas de bosques costeros entre la Ruta Interbalnearia, el arroyo Solís Chico, y el arroyo Sarandí. Presenta arquitectura doméstica pintoresquita de las tres primeras décadas del siglo XX, cascos fundacionales, arquitectura hotelera y domestica Art Decó. (Hotel La Floresta). Este primer tramo tiene vinculaciones en cuanto a características y lógicas con Atlántida y también a partir de la conurbación que se genera en la conexión con Estación Floresta. Esta vinculación existe desde los orígenes de la urbanización. Actualmente Estación La Floresta se ha expandido hacia la costa, vinculándose con su balneario de referencia.

Guazú-virá. El balneario se desarrolla predominante a lo largo del eje principal, la Avenida Central, perpendicular a la costa en el cual se genera la mayor concentración de viviendas. "Perpendicular a la costa extendida". La trama urbana es rectangular y está compuesta por 28 manzanas organizadas 14 a cada lado del eje.

Arroyo el Bagre, San Luis. El núcleo urbano del balneario crece según varios ejes, "expandido", su trama es rectangular y está atravesada por diagonales generando en los cruces espacios públicos, carece de rambla costanera y presenta diferentes densidades de viviendas, incluso sobrepasa la Ruta Interbalnearia, conformando San Luís Norte. Este balneario cuenta con la mayor cantidad de población permanente del área de estudio y tiene la comunidad de pescadores artesanales más grande de Canelones.

Los Titanes, Arroyo La Tuna, La Tuna. Este balneario presenta una extensión urbana homogénea de la Ruta a la Rambla, es "compacta". Existe un eje principal, la avenida 11 de Agosto, que conecta la Interbalnearia con la costa en el caso de los Titanes y en la Tuna la calle Bohane y Gral. Artigas. Las tramas son diferentes en cada uno de los balnearios. Presenta arquitectura domestica pintoresquista de las tres primeras décadas del siglo XX. 


\section{ID_INVESTIGACIONES}

Arquitectura hotelera y doméstica Art Decó. (Hotel La Tuna) de las décadas del 30 y 40 .

Araminda, Sta. Lucía del Este. El núcleo urbano del balneario crece según varios ejes: "expandida", cuenta con sectores no urbanizados y cuñas de bosque. La Rambla General Rovira en Araminda y la de Santa Lucia, están alejadas de la costa.

Biarritz, Cuchilla Alta, Sierra del Mar. Estos balnearios se organizan a través de una rambla a la cual se agregan extensiones secundarias "expandida con agregados costeros". La trama es rectangular contra la costa y en base a diagonales cuando se acerca a la ruta. Se agregan hacia los lados de Cuchilla Alta, áreas urbanizadas, con una dirección tensionada por la costa hacia el Este continuándose la Rambla Treinta y Tres con la calle Diagonal Oeste, hacia el oeste Biatrriz y hacia el norte se conecta por la ruta 103 con enclaves rurales Piedras de Afilar y Capilla de Cella. Centro poblado de referencia zonal por los servicios con los que cuenta.

Santa Ana, Balneario Argentino, Paraíso Suizo. El balneario Santa Ana se organiza a lo largo de una calle paralela a la costa generando un amanzanado estrecho y largo. Los balnearios Argentino y Paraíso Suizo se desarrollan predominantemente a lo largo del eje principal perpendicular a la costa: "lineal, perpendicular a la costa". En el balneario Argentino es la calle 30 metros.

Jaureguiberry. Este balneario crece según varios ejes, con distintas densidades: "expandido". Esta urbanización es partida en dos cuando la Ruta Interbalnearia fue conformada. Este último tramo tiene conexiones muy fuertes con el departamento de Maldonado, concretamente con Piriápolis. Existe una relación de dependencia de servicios tanto educativos como médicos, generada por la débil conexión interna ínter-balnearios en este tramo. El urbanista generó al centro de la trama un gran sector destinado a espacio 
ID_INVESTIGACIONES

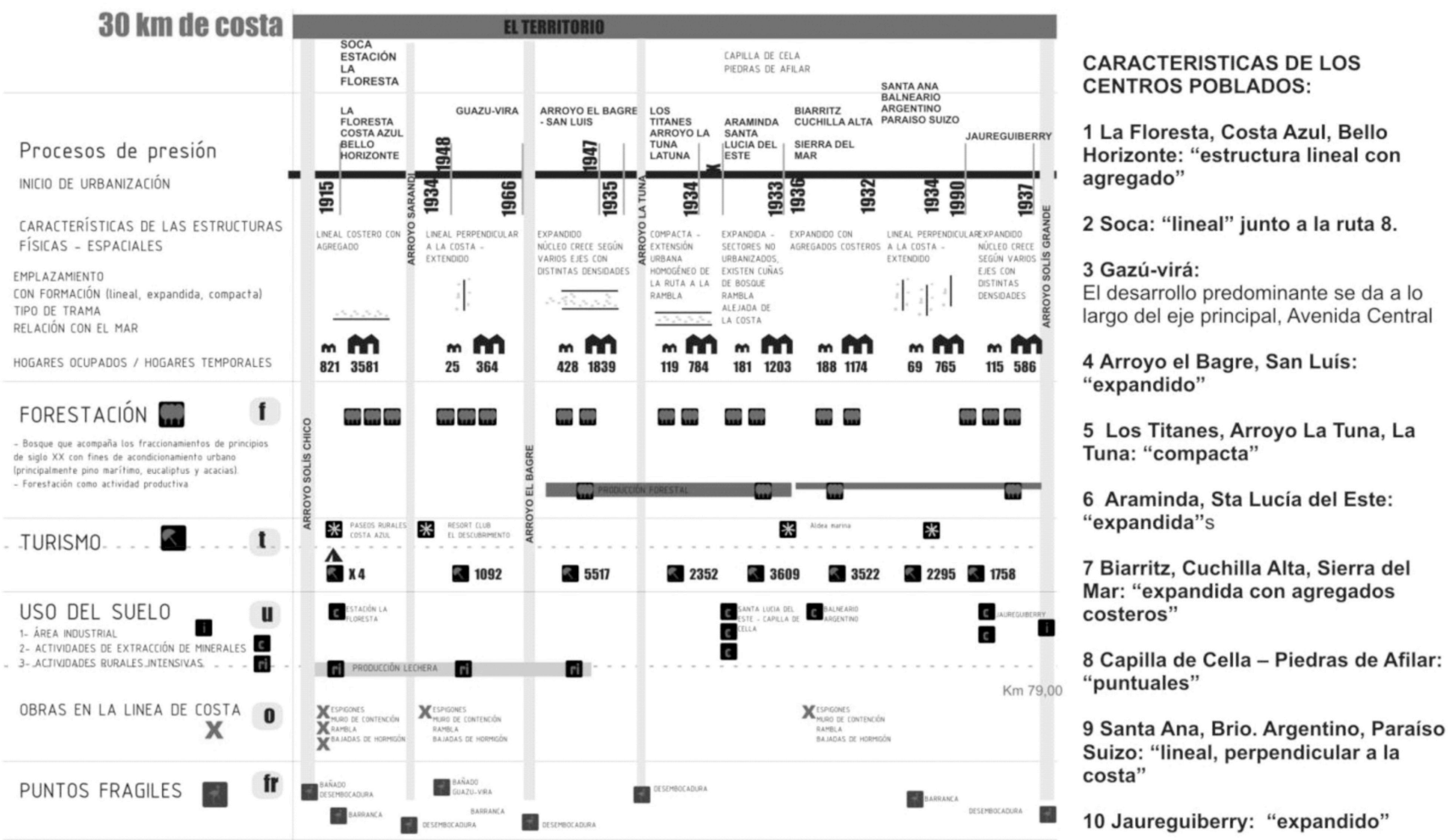

Características de los centros poblados, su proceso de urbanización y su desarrollo en

el tiempo del tramo de costa entre los arroyos Solís Chico y Grande según origen del

balneario, tipo de urbanización, infraestructura, cantidad de población y usos del suelo 


\section{ID_INVESTIGACIONES}

público, que desde hace unas décadas es utilizado por diferentes colonias de vacaciones. Este tema está actualmente en la agenda municipal.

Los impactos de la ocupación y el uso del territorio sobre el espacio costero y en especial sobre los puntos frágiles ${ }^{4}$ son variados. Además de los desequilibrios que ocasionan en los sistemas ambientales, generan otros impactos asociados (pérdida de valor estético y de uso de la playa, pérdida de calidad ambiental, erosión y retroceso de línea de costa, derrumbe de viviendas y estructuras de protección sobre la playa), que repercuten en las infraestructuras construidas por el hombre, acarreando grandes pérdidas económicas.

\section{BANDA ESTUARINA}

La descarga del Río de la Plata en el Océano Atlántico forma un sistema fluviomarino que genera fuertes gradientes ambientales en términos de turbidez $y$ salinidad. Asimismo constituye una barrera biogeográfica natural para varias especies distribuidas a lo largo de las costas atlánticas. Esta banda pertenece a dos zonas: la estuarina interna desde la desembocadura del Río Santa Lucía hasta la Floresta (el frente salino), y la externa, desde Costa Azul (Canelones) y Playa Santa Mónica (Maldonado). En este espacio coexisten una serie de factores naturales, como mareas, corrientes, vientos, variaciones climáticas, biodiversidad, que generan características ambientales muy versátiles, debido a la interacción entre el agua dulce proveniente del Río de la Plata, el agua marina del océano Atlántico y la atmósfera, generando una gran heterogeneidad ambiental "en términos de masas de agua (cálidas, templadas, frías, dulces, saladas y salobres), fisiografía (islas, puntas rocosas, marismas,

${ }^{4}$ Puntos Frágiles: Se pueden definir como zonas sensibles en donde cualquier intervención dispara procesos, modificando el equilibrio del sistema. 


\section{ID_INVESTIGACIONES}

playas arenosas, barrancas) y geología (fondos arenosos), lo que genera una extensa variedad de hábitat, utilizados por una gran diversidad de especies" (Freplata, 2004). Se caracteriza por ser un área con gran biomasa zooplanctónica, además de ser área específica de reproducción y cría de varias especies (corvina blanca, corvina negra, pescadilla) así como por albergar especialmente tortugas marinas, cangrejales y un banco costero de mejillones, así como lacha y anchoa.

Por otro lado en el área del Río de la Plata y su Frente Marítimo habitan, en forma permanente o transitoria, varias especies acuáticas cuya supervivencia a nivel mundial enfrenta distintos grados de amenaza, de acuerdo con la categorización de la Unión Internacional para la Conservación de la Naturaleza y los Recursos Naturales (IUCN, 2004). Se reconocen tres grupos de especies carismáticas y paraguas, y al mismo tiempo con problemas de conservación: lobos marinos (Otaria flavescens y Artocephalus australis), tortugas de mar (tales como Chelonya mydas) y ballenas (Eubalaena australis y Pontoporia blainvielli, entre otras).

Con la creciente presión de uso del mar, la protección de los ecosistemas marinos resulta clave. Numerosos estudios, en particular Brazeiro et al. (2003) han realizado una evaluación ecológica de la biodiversidad acuática del Río de la Plata y Frente Marítimo, enfocado en la identificación de áreas prioritarias para la conservación y el manejo. Otro estudio relevante es "Hacia un manejo Ecosistémicos de Pesquerías. Áreas Marinas Protegidas en Uruguay" donde se identifican y categorizan diez sitios como potenciales AMPs. En este sentido el estado prevé generar un sistema de áreas protegidas para preservar recursos acuáticos. Se enumeran así las áreas definidas para nuestra área de estudio:

Área Marina Protegida: Arroyo Pando-Solís Chico. Desembocadura del Arroyo Pando y Solís Chico abarca una superficie de $270 \mathrm{~km} 2$. Existen sistemas litorales y submareales somero de crías de peces de importancia comercial. En 


\section{ID_INVESTIGACIONES}

ambas desembocaduras se han detectado la máxima densidad poblacional de juveniles de peces de la costa. (Defeo et al, 2009).

Área Acuática Prioritaria: Los bajos del Solís (desde Isla la Tuna hasta Piriápolis) por ser área de reproducción y cría de peces y zona de alimentación de la tortuga verde.

Área Marina Protegida: Arroyo Solís Grande (Brazeiro et al, 2006, Defeo et al 2009). Los bajos del Solís (desde Isla la Tuna hasta Piriápolis) por ser área de reproducción, de cría de peces y zona de alimentación de la tortuga verde.

\section{CORREDORES}

Esta mirada implica detenernos en dos tipos de estructuradores, los biológicos y los infraestructurales. Estos corredores propician una mirada del territorio en forma integral, ya que atraviesan diferentes paisajes, conectan o separan espacios y surgen como articuladores del territorio. La inclusión de esta dimensión en nuestro enfoque de trabajo nos acerca a una propuesta más íntima y acorde a la realidad del área.

Los corredores longitudinales: Existen tres grandes estructuradores que cruzan el área en sentido longitudinal, la Ruta Interbalnearia, la vía férrea y la Ruta 8 Brigadier General Lavalleja.

También en algunos sectores existe la Rambla Costanera: Este modelo está consolidado en La Floresta y Costa Azul y Cuchilla Alta, en algunos casos aportando un recorrido paisajístico de gran interés. Tiene niveles de consolidación más bajos en otros balnearios y en algunos lugares se encuentra ocasionalmente invadida por la movilidad de las dunas existentes.

Los corredores transversales: Unen el área rural con los balnearios costeros. Conforman sin lugar a duda un sistema donde las actividades "aguas arriba" 
ID_I N VESTIG AC I O NES

tarde o temprano repercuten en la cuenca y en la costa, por lo que es importante compatibilizar los usos.

Sistema en Peine: Sistema de acceso perpendicular a la playa desde la Ruta: Avenida Artigas (La Floresta) - Ruta 35, eje que se define por la Avenida Artigas del balneario La Floresta y la Ruta 35 .

Avenida Central (Guazú-Virá). La Avenida central del balneario Guazu-Virá hasta la Ruta Interbalnearia.

Avenida Artigas (Cuchilla Alta) - Ruta 70. Avenida General Artigas del balneario Cuchilla Alta y las Rutas 70 y 9 .

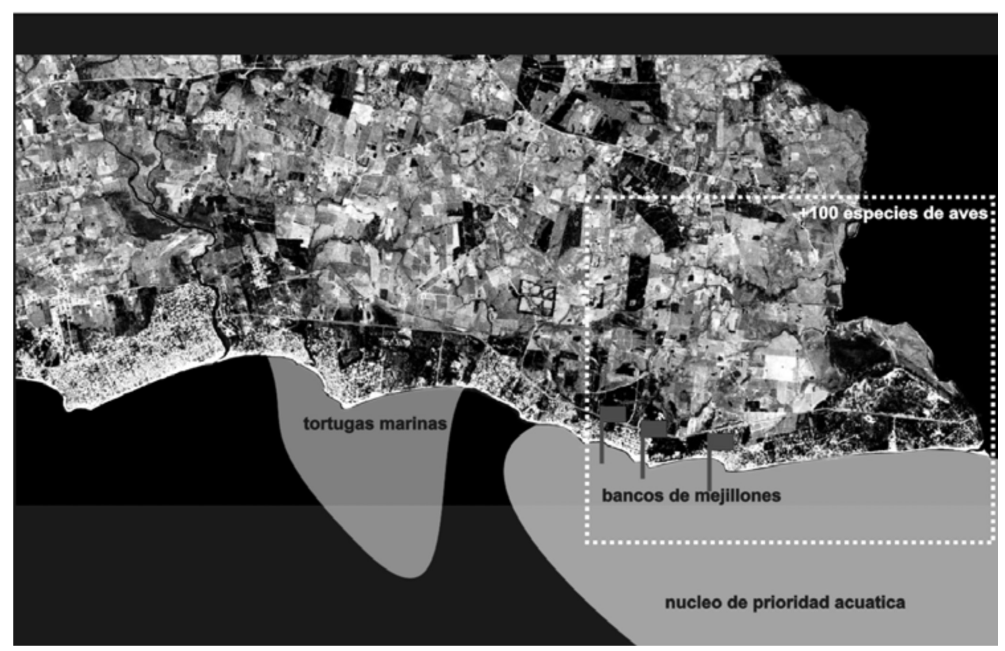

Áreas acuáticas prioritarias 


\section{ID INVESTIGACIONES}

Sistema de corredores biológicos: Las principales vías de drenaje superficial encauzadas están constituidas por las cuencas y sub-cuencas de los arroyos: Solís Chico, el Bagre, la Tuna, la Coronilla, Sarandí y Solís Grande. Las mismas se encuentran enmarcadas en una topografía que pasa de colinas y lomadas al norte hacia un relieve llano de baja altitud sobre el borde costero, al cual corren perpendicularmente estas vías de drenaje superficial. La centralidad del recurso hídrico para los grupos humanos hace de las cuencas territorios de relevancia económica, ambiental y social, quedando comprendido bajo este enfoque diferentes unidades político-administrativas, sistemas de actores y modos productivos.

Éstas tienen diferentes grados de calidad y niveles de conservación o degradación ambiental. A manera de ejemplo se puede señalar las cuencas de los Arroyos Bagre y La Tuna como áreas de una buena calidad ambiental, pues mantiene sus bosques ribereños y ecosistemas asociados en buenas condiciones. Los principales corredores biológicos del área son: Arroyo Solís Chico, Arroyo Sarandí (monte ribereño), Arroyo El Bagre (monte ribereño), Arroyo La Tuna (monte ribereño), Arroyo La Coronilla (monte ribereño), Arroyo Solís Grande (monte ribereño + humedal)

\section{CONCLUSIONES}

Hemos definido el área como pieza única de relaciones diversas y complementarias, donde confluyen dos realidades al Norte y al Sur de la Ruta Interbalnearia. Esta unidad espacial está constituida por una gran diversidad de componentes históricos, sociales y ambientales que interactúan entre sí y con el territorio. Todos estos factores unen el norte de la ruta Interbalnearia con los balnearios en la costa estableciendo claras relaciones entre el área productiva y la costa propiamente dicha, haciendo necesario abordar el territorio en forma integral. 


\section{ID_INVESTIGACIONES}

Señalamos que la fortaleza de nuestra área desde el punto de vista del paisaje cultural es la diversidad de paisajes dado por los pobladores y el territorio (como matriz social-ambiental) que determinan, desde sus dinámicas propias, elementos capaces de aportar nuevas formas de interpretar e intervenir en el territorio. En el área de estudio se despliegan así distintos escenarios soportes de paisajes diversos: paisajes rurales, paisajes balnearios y estuarinos se alternan y entrelazan en $30 \mathrm{Km}$ de costa generando un territorio que si bien tiene ya identidad propia aún está lejos de explotar su total potencial en términos de paisaje.

Banda Rural: La existencia de miradores naturales generan una ruta panorámica, en toda el área y la posibilidad de ofrecerle al turista condiciones naturales preservadas, así como un manejo productivo sostenible que se manifiesta o se luce aguas abajo y en aprovechamiento de los recursos naturales.

En relación a la conectividad y accesibilidad, existe en el área una red débil de conexiones viales al Norte sumado a una falta de transporte público que conecte algunos lugares rurales con el resto del territorio, como Capilla de Cella y Piedras de Afilar. Tampoco existe un sistema de transporte interbalneario.

Esto genera dificultades de integración entre las diferentes comunidades y dificulta en términos de recurso paisajístico el disfrute de determinados enclaves con valores naturales y culturales. La Ruta Interbalnearia sigue siendo el gran estructurador y conector del tramo, solo compitiendo con la rambla en los sectores que existe.

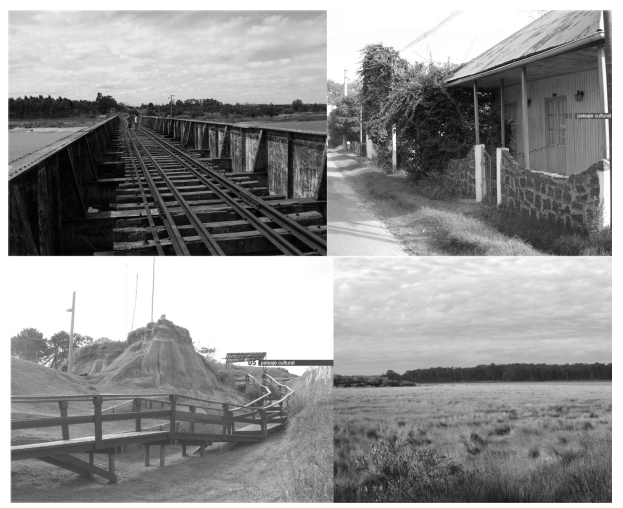

Diversidad de paisajes culturales existentes en el área. 


\section{ID_INVESTIGACIONES}

Las características de la producción agropecuaria en el área le dan un perfil variado y es diversificada, pero se desarrolla básicamente en la misma época del año.

Banda Balnearia: Su fortaleza es la baja antropización. Algunos de estos enclaves llegan a tener hasta un $20 \%$ como máximo de viviendas ocupadas permanentemente en relación al total de existentes (La Floresta, San Luis y Cuchilla Alta; INE, 2004). Estos balnearios poco densos (salvo excepciones) están separados por "intersticios verdes sin urbanizar". La forestación del área está dada sobre la base de especies de "pinos", "eucaliptos" y "acacias", que fueron utilizados para detener las arenas en las costas del Río de la Plata al iniciar la colonización de los terrenos ubicados en la zona costera, permitiendo su fraccionamiento para su posterior urbanización. Esta alta relación de espacios verdes que conforman intersticios costeros, junto con el verde como equipamiento urbano, es una característica de la zona muy valorada desde el punto de vista del paisaje cultural.

La mayoría de las playas del área son arcos entre puntas o cabos que presentan un transporte de arena derivado de corrientes longitudinales (Nagy et al., 2002).

Si bien la zona cuenta con baja densidad de ocupación del suelo y varias áreas conservan un alto grado de "naturalidad", el sistema de puntos frágiles se encuentra hoy afectado con diferentes grados de intensidad, situación que podría agravarse si no se interviene sobre algunas de las acciones que generan esta tendencia. Por un lado el balance negativo de sedimentos afecta hoy la playa Oeste de La Floresta (alcanzando un alto nivel de impacto) y el sector Este de la playa de Cuchilla Alta. La pérdida de áreas de humedal y 


\section{ID_INVESTIGACIONES}

espacios verdes (bosque urbano, bosque costero, corredores biológicos) está directamente relacionada con la disminución de biodiversidad.

En el área aún no se ha implementado la planificación sobre el crecimiento urbano y sobre el sistema de drenajes. Este proceso podría impactar fuertemente en dos importantes elementos caracterizadores del paisaje local: la playa (pérdida de arena y contaminación de arena por escorrentía), y los intersticios verdes urbanos (pérdida por sustitución).

Tal vez en este sentido la banda más reconocida, que cuenta ya con un registro en el imaginario social y cultural a nivel nacional es la balnearia. En ella aparecen dos sistemas de elementos configuradores de paisaje que le aportan sus principales características: por un lado una trama compuesta por el bosque de pinos o eucaliptos asociado a una vivienda unifamiliar tipo "chalet", y por otro la rambla costera como balcón al mar, interfase entre tierra y agua, registro y soporte de múltiples actividades sociales. En el caso de la rambla costanera la arquitectura asociada (se destacan aquí como hitos, hoteles e importantes chalets de principios del siglo XIX) y algunos enclaves naturales particulares (miradores naturales y puntas rocosas) generan puntos significativos en este recorrido cotidiano.

Banda Estuarina: La utilización del recurso pesquero es una actividad que en época de zafra recibe cada vez más comunidades de pescadores provenientes de otras localidades, así como también aficionados a la pesca deportiva (costa y mar). Por otro lado la realización de deportes náuticos en arroyos y playas es una de las actividades vinculadas al ocio, características del tramo así como también el desarrollo de nuevas actividades como el proyecto de un nuevo puerto deportivo, la posible ubicación de una regasificadora en Jaureguiberry y la cercanía con el Canal de Navegación de acceso a Montevideo. Estas actividades se conjugan con tres áreas marinas prioritarias para la protección de la biodiversidad. 


\section{ID_INVESTIGACIONES}

\section{DISCUSIÓN}

Inicialmente queremos dejar en evidencia que analizamos y consideramos al área como una pieza única. Esta compleja complementariedad tiene su origen en la forma en que se desarrolló y estimuló el uso de la zona costera canaria, la conformación de pequeños poblados, que oficiaron de paradas, esperas del pasaje del tren por la zona, para conectarse con la zona costera. Un claro ejemplo son las paradas de Soca o Piedras de Afilar, lugares que surgieron hace 100 años con otra nomenclatura y que hoy ya no presentan relevancia, por no cumplir la función para la que fueron creadas.

La consideramos como una unidad espacial constituida por una gran diversidad de componentes históricos, sociales y ambientales que interactúan entre sí y con el territorio. Todos estos factores unen el Norte de la Interbalnearia con los balnearios en la costa estableciendo claras relaciones entre el área productiva y la costa propiamente dicha, haciendo necesario abordar el territorio en forma unitaria.

Para definir y lograr este objetivo nos preguntamos:

¿Es posible organizar una "cooperación entre los centros poblados y su entorno rural" bajo formas renovadas de colaboración y complementariedad?

Es aquí donde pueden inventarse soluciones adaptadas a las potencialidades locales para concretar la cohesión social y un desarrollo sostenible del área.

¿Cómo puede ser la ordenación de este territorio desde el punto de vista del paisaje cultural?

¿Cómo encontrar mecanismos que preserven y potencien el paisaje cultural, la calidad, la identidad y, por tanto la "sostenibilidad" del área? 


\section{ID INVESTIGACIONES}

Proponemos construir una "visión compartida" del territorio a partir de un desarrollo que cuide minuciosamente las características naturales del área, y en ese marco reconozca el valor tangible e intangible del mismo, logrando un posicionamiento competitivo dentro del litoral uruguayo.

\section{RECOMENDACIONES}

Consideramos importante revalorizar esa dependencia recíproca entre el Norte y el Sur que existió en los orígenes de la ocupación de la zona y que continúa en la identidad de los pobladores. Creemos que ese Norte, pujante y productivo, debe marcar la diferencia fomentando la producción sustentable, desplegando herramientas productivas valorando la trascendencia ambiental y socioeconómica del ecosistema que integran. Estos corredores transversales que unen el área rural con los balnearios costeros conforman sin lugar a dudas un sistema complejo.

Entendemos que toda la pieza posee un elevado valor ecológico y paisajístico muy singular, a conservar. Nuevas formas de recorrer y usar los territorios del ocio plantean oportunidades a la hora de revisar y proyectar los vínculos con las otras dos bandas. La banda rural poseedora de un patrimonio cultural (estaciones y trazas ferroviarias) y natural (teselas, miradores, corredores

biológicos), no explotado, tiene allí sus principales activos en términos de paisaje. Y por último el mar (banda estuarina), plantea en su posible lectura y manejo el principal desafío para los hábitat costeros. Desafío que surge cuando dejamos de "mirarlo" como telón de fondo del paisaje costero, para entenderlo como un paisaje con vida y estructura propia: nicho de biodiversidad, soporte de actividades múltiples y configurador dinámico de nuestra costa. En este 


\section{ID I N VESTIG AC I O NES}

sentido parece necesaria la necesidad de fortalecer el tejido social existente en el área, generando instancias de articulación entre lo rural, los centros poblados y la costa para concienciar a la población de los recursos tangibles e intangibles, y de la importancia de su cuidado y preservación.

\section{BIBLIOGRAFÍA:}

ALVEAR, D (1837). Diario de la segunda división de límites al mando de D. Diego de Alvear con la descripción de su viaje desde Buenos-Aires. En http://www.cervantesvirtual.com/servlet/SirveObras/01159296108929369658813/p00.

BRAZEIRO, A Y DEFEO, O. (2006). "Bases ecológicas y metodológicas para el diseño de un Sistema Nacional de Áreas Marinas Protegidas en Uruguay". Bases para la conservación y el manejo de la costa uruguaya. VIDA SILVESTRE URUGUAY, Montevideo. ixiv+ 668pp.

DEFEO, O; HORTA, S; CARRANZA, A; LERCARI, D. DE ALAVA, A; GOMEZ, J; MARTINEZ, G; LOYZOYA, P; CALENTANO, E. (2009). Hacia un manejo Ecosistémicos de Pesquerías. Áreas Marinas Protegidas en Uruguay. Facultad de Ciencias - DINARA.

FREPLATA. (2004). "Análisis Diagnóstico Transfronterizo del Río de la Plata y su Frente Marítimo". Documento Técnico. Proyecto Protección Ambiental del Río de la Plata y su Frente Marítimo. Proyecto PNUD/GEF/RLA/99/G31.

GALLICHIO E., CANTÓN VÍCTOR Y SCIANDRO, J.L. (2004.) Estudio Sinóptico Gestión Costera en Uruguay: Estado Actual y Perspectivas. Ecoplata Montevideo, Uruguay.

GARCÍA, R. (1996). Proyecto Corredor Biológico Mesoamericano. Informe Técnico Regional. CCAD. Costa Rica. 108p

INSTITUTO NACIONAL DE ESTADISTICA (2004). Censo de General de Población y Hogares y de Viviendas. República Oriental del Uruguay. 
ID_I N VESTIG ACIONES

LEZAMA, A. La gestión del patrimonio cultural subacuático uruguayo, Departamento de Arqueología, Facultad de Humanidades y Ciencias de la Educación, Montevideo, Uruguay. Sitio Web http://www.pas.edu.uy. Fecha de consulta 10 de marzo 2009.

MUSSO, C. (2007). "Las Escalas óptimas de Gestión para el Territorio Uruguayo y su Definición de Criterios para su Articulación e Instrumentación". Cuadernos del Territorio Serie Tesis de Maestría en Ordenamiento Territorial Ministerio de Vivienda Ordenamiento Territorial y Medio Ambiente - Dirección Nacional de Ordenamiento Territorial Universidad de la República/ Facultad de Arquitectura. Montevideo.

NAGY, G. (2001). El Río de la Plata. Investigación para la Gestión del Ambiente, los Recursos Pesqueros y la Pesquería en el Frente Salino. Programa Ecoplata. Montevideo, Uruguay.

PANARIO, D. (2000). Perfil Ambiental del Uruguay / 2000. Editorial Nordan-Comunidad, Montevideo.

SAUER, Carl O. (1925). The morphology of landscape. University of California Publications in Geography 2, (pag19-54).

SHIVA, V. (2003). Las guerras del agua. Privatización, contaminación y lucro. Siglo XXI Editores. Bs As. Argentina.

TORRES, A. (2007). La mirada Horizontal. El paisaje costero de Montevideo. Facultad de Arquitectura Universidad de la República. Ediciones de la Banda Oriental. Montevideo. 
ID_ I N VESTIGACIONES

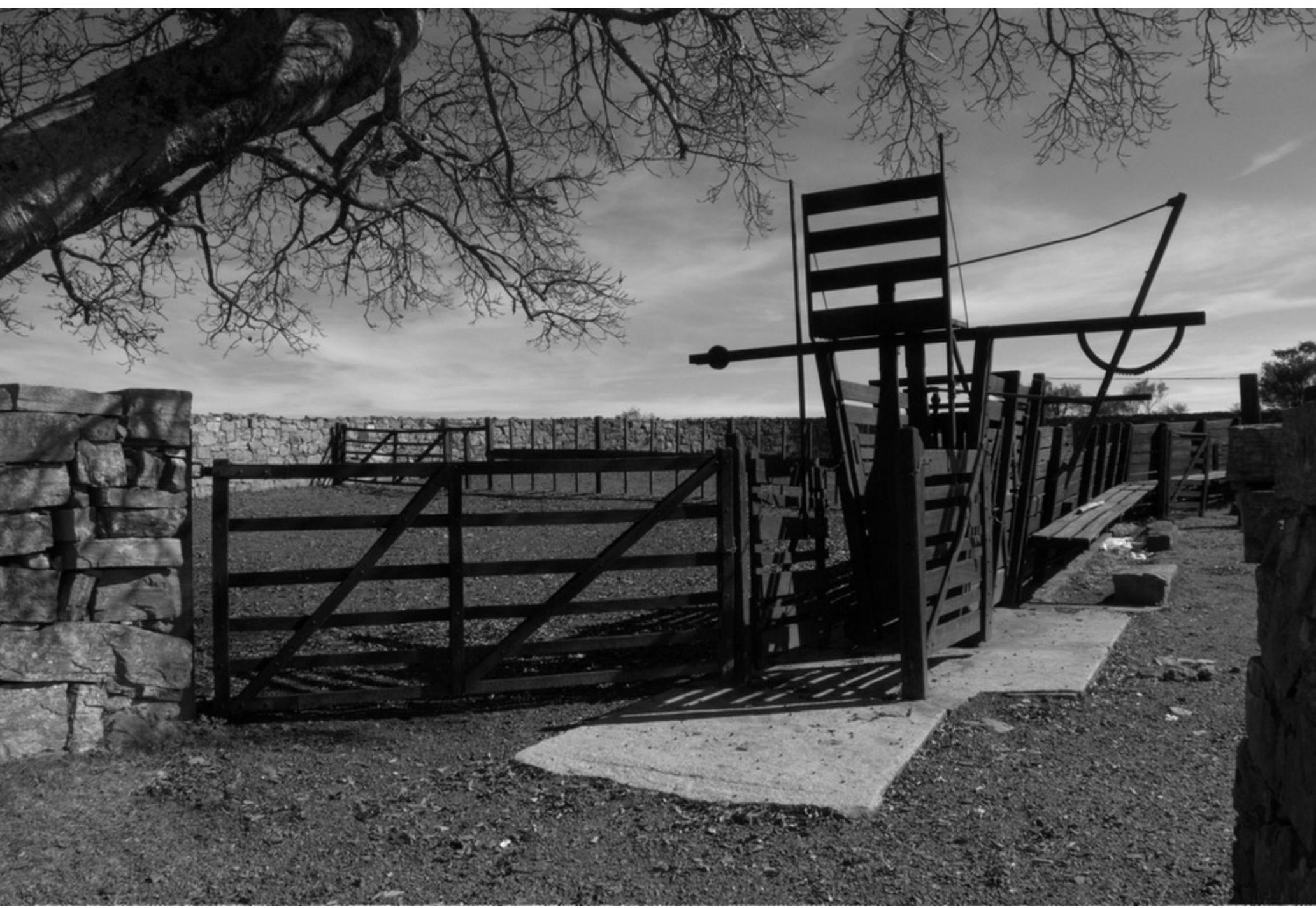

Estancia Camino Melo. Fuente: foto cedida por el Servicio de Medios Audiovisuales

Facultad de Arquitectura, autora Verónica Solana 